\title{
Magnetite Thin Films
}

\author{
'JOSEPH S.-Y. FENG, CHRISTOPHER H. BAJOREK, AND MARC-A. NICOLET
}

Abstract-A low temperature process for converting hematite $\left(\alpha-\mathrm{Fe}_{2} \mathrm{O}_{3}\right)$ thin films into magnetite $\left(\mathrm{Fe}_{3} \mathrm{O}_{4}\right)$ is described. The films produced are unambiguously identified as magnetite by several complementary methods of analysis. These include $\alpha$-backscattering spectrography, X-ray powder diffractometry, and observations of electrical, magnetic, and optical properties.

The phase diagram of the iron-oxygen system has only two compounds below about $560^{\circ} \mathrm{C}$. In the presence of excess oxygen, hematite is the stable compound, while magnetite is stable in the presence of excess iron [1]. This suggests that hematite can be converted to magnetite by providing excess iron in an oxygen-free ambient. Recent migration studies in other binary and ternary systems have shown that such transformations can occur rapidly, even at low temperatures, in thin films [2]. We have successfully utilized this concept to produce magnetite films in the sub-micron range.

Hematite thin films are made by first evaporating high purity iron in a vacuum of better than $10^{-6}$ Torr. The pure iron films are then annealed at $450^{\circ} \mathrm{C}$ to $550^{\circ} \mathrm{C}$ in $\mathrm{O}_{2}$ or air at $1 \mathrm{~atm}$. This forms a clear red oxide film. Antiferromagnetic $\alpha-\mathrm{Fe}_{2} \mathrm{O}_{3}$ is the only stable iron oxide in an oxygenrich ambient at these temperatures [1]. The hematite is then covered by a second layer of pure iron. The amount required for complete conversion to magnetite is only about $12 \%$ of the quantity of original iron, but this second film is typically chosen to be over $50 \%$ of the thickness of the original film to provide surplus iron that will protect the oxide film against possible undesired reactions with the annealing ambient. The overcoated hematite film is then annealed at $350^{\circ} \mathrm{C}$ to $400^{\circ} \mathrm{C}$ in an inert ambient, normally a vacuum of better than $10^{-7}$ Torr. This converts the $\alpha-\mathrm{Fe}_{2} \mathrm{O}_{3}$ to $\mathrm{Fe}_{3} \mathrm{O}_{4}$. The time required for completion of the reaction is unknown, but the yield has been $100 \%$ for anneals longer than eight hours. The excess iron can then be removed in either dilute $\mathrm{HNO}_{3}$ or a solution of one part volumetric $\mathrm{Br}$ in five parts $\mathrm{CH}_{3} \mathrm{COOCH}_{3}$. Magnetite films $1 \mathrm{~cm}$ in diameter and from $2000 \AA$ to $3000 \AA$ thick have been prepared on Corning 0211 glass, $\mathrm{Si}$, thermally oxidized $\mathrm{Si}$, alumina, sapphire, and fused quartz substrates. Optical microscopy with $300 \mathrm{X}$ magnification shows no evidence of pinholes in either the original iron or any of the resulting oxide films. The thickness of the original iron film determines that of the hematite film, which in turn controls the thickness of the final magnetite film.

Mánuscript received February 25, 1972. Paper 3.1, presented at the 1972 INTERMAG Conference, Kyoto, Japan, April 10-13. This work was supported in part by the Office of Naval Research and the NASA Langley Research Center.

J. S.-Y. Feng and M.-A. Nicolet are with the California Institute of Technology, Pasadena, Calif. 91109.

C. H. Bajorek was with the California Institute of Technology, Pasadena, Calif. 91109. He is now with the IBM Thomas J. Watson Research Center, Yorktown Heights, N.Y, 10598.

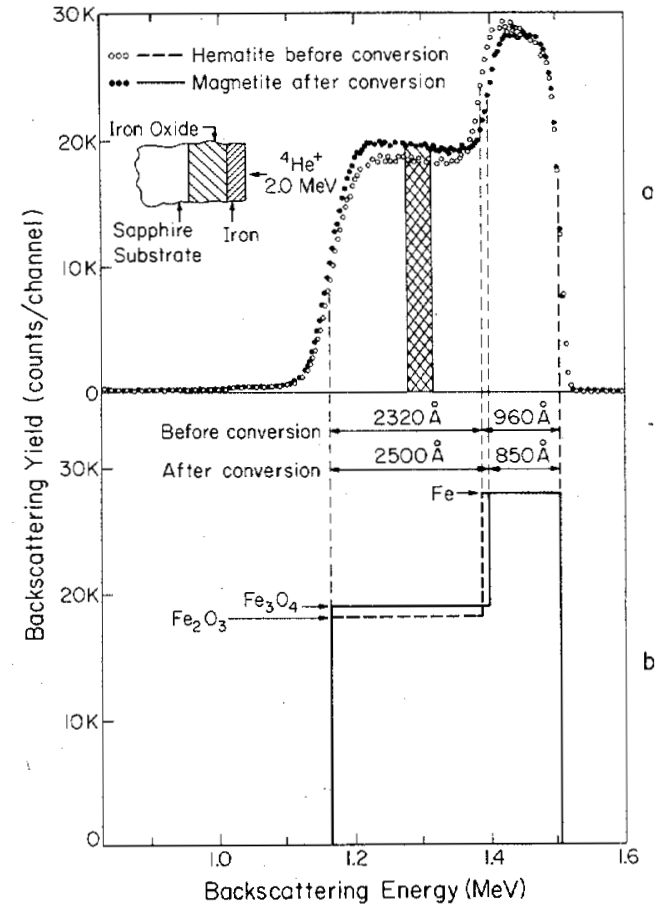

Fig. 1. (a) The iron signals of $2.0 \mathrm{MeV}^{4} \mathrm{He}^{+}$ions backscattered from hematite covered with iron on sapphire substrates before (o) and after $(\bullet$ ) conversion to magnetite. (b) Decomposition into step signals. The pure iron film on the surface generates the higher step. The lower step is due to the oxide film underneath. The results show that after conversion the pure iron film is thinner while the iron content of the oxide has increased. The $\mathrm{Al}$ and $\mathrm{O}$ signals appear below $800 \mathrm{keV}$.

The thickness of the resulting magnetite film was estimated from bulk properties to be a factor of 2.34 greater than the initial iron film thickness.

The transition from hematite to magnetite was verified by backscattering spectrography with $2.0 \mathrm{MeV}^{4} \mathrm{He}^{+}$ions. In Fig. $1 \mathrm{a}$, the iron signal of a film of hematite covered with iron on a sapphire substrate taken before anneal is compared with that of another film taken after conversion. Figure $1 \mathrm{~b}$ shows the same data decomposed into step signals. The higher step corresponds to the pure iron on the surface, while the lower step is produced by the iron in the oxide. The figure shows that after conversion the amount of iron contained in the oxide has increased at the expense of the pure iron film. The change in both the thickness and the iron content of the oxide is consistent with the transformation to magnetite. The yields averaged over ten channels $(1279 \mathrm{keV}-1317 \mathrm{keV}$, dashed areas) give an iron backscattering yield ratio of 0.948 : 1.000 before and after conversion. Assuming Bragg's rule, the expected $\mathrm{Fe}_{2} \mathrm{O}_{3}: \mathrm{Fe}_{3} \mathrm{O}_{4}$ yield ratio is 0.953:1.000.

The results of X-ray powder diffraction analysis using $\mathrm{Cu}-\mathrm{K}_{\alpha}$ radiation are shown in Fig. 2. The background is due to the glass substrate under the converted $2400 \AA$ oxide film, 


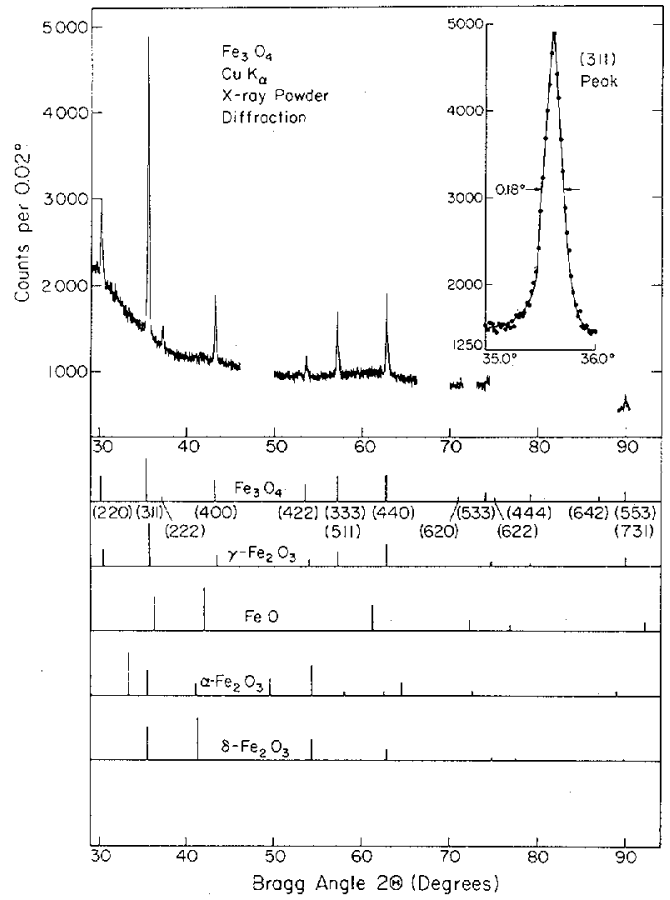

Fig. 2. X-ray powder diffraction pattern produced by a converted $2400 \AA$ film on a Corning 0211 glass substrate using $\mathrm{Cu}-\mathrm{K}_{\alpha}$ radiation (top). Powder diffraction lines for various iron oxides (bottom). (311) peak (inset).

while gaps in the background indicate regions in which no measurements were taken. The principal powder diffraction lines for several iron oxides are shown below the diffractometer data, with the height indicating the approximate relative amplitudes. The observed diffraction lines are consistent with a polycrystalline cubic structure and a lattice parameter of $8.391 \pm 0.003 \AA$. The only phase consistent with this structure is magnetite. The one-to-one correspondence of the diffraction pattern peaks to $\mathrm{Fe}_{3} \mathrm{O}_{4}$ lines excludes the possibility of significant amounts of wüstite $(\mathrm{FeO})$ or most phases of $\mathrm{Fe}_{2} \mathrm{O}_{3}$. The lattice parameter of maghemite $\left(\gamma-\mathrm{Fe}_{2} \mathrm{O}_{3}\right)$ is very close to that of magnetite, but this phase is eliminated by the increased iron content evident in the backscattering data. The peak identified with the (311) planes of $\mathrm{Fe}_{3} \mathrm{O}_{4}$ is detailed in the inset of Fig. 2. The half-width of less than $0.2^{\circ}$ indicates that the microcrystals are relatively free of strains and defects.

Electrical properties of the films were measured in the four-point probe and van der Pauw configurations. At room temperature the resistivity is $8.5 \times 10^{-3} \Omega \mathrm{cm}$. This value is reproducible and the conduction is not due to any residual iron on the surface. The bulk resistivity at room temperature is about $7 \times 10^{-3} \Omega \mathrm{cm}$ [3]. The sign of the Hall voltage generated indicates that the carriers are electrons.
The magnetic properties of some films were measured with a $60 \mathrm{~Hz}, 1 \mathrm{kOe}$ peak field range hysteresis loop tracer, a $20 \mathrm{kOe}$ field range force balance magnetometer, and a perpendicular ferromagnetic resonance (FMR) spectrometer in the 1 to $8 \mathrm{GHz}$ frequency range. The coercivity and remanence of films on glass substrates ranged from 220 to $280 \mathrm{Oe}$ and 50 to $60 \%$, respectively. The coercivity and remanence of films on $\mathrm{Si}$ and oxidized $\mathrm{Si}$ substrates ranged between 300 and 400 Oe and 45 to $55 \%$, respectively. The observed coercive fields are consistent with previously reported values [4]. The films showed no measurable planar uniaxial anisotropy. The saturation magnetization of the films determined for six films from FMR and force balance magnetometer measurements is $4 \pi \mathrm{M}=5.2 \pm .3 \mathrm{kG}$ as compared to $6.0 \mathrm{kG}$ for bulk magnetite [5]. The agreement of the FMR and magnetometer measurements is consistent with the absence of any significant perpendicular anisotropy. The gyromagnetic ratio as determined from FMR is $\gamma / 2 \pi=1.95$ $\pm .10 \mathrm{mHz} / \mathrm{Oe}$. All FMR line widths were less than $100 \mathrm{Oe}$, much sharper than the 1700 Oe reported by Banks et al. [6] or the 1500 Oe reported for bulk magnetite [7] .

The most apparent indication of a phase transition is the color change of the films which can most easily be observed with a transparent substrate. Hematite films are transparent and red, and this color is still visible after the films are overcoated with iron. After conversion the films appear black. These colors are consistent with those of bulk hematite and magnetite.

\section{ACKNOWLEDGMENT}

Much of this work would not have been possible without the guidance and assistance provided by F. B. Humphrey, G. O. Johnson, and C. H. Wilts. We are indebted to P. E. Duwez for the X-ray powder diffractometer measurements and R. D. Pashley for electrical measurements.

\section{REFERENCES}

[1] M. Hansen, Constitution of Binary Alloys, New York: McGrawHill, 1958 , p. 689 .

[2] A. Hiraki, M-A. Nicolet, and J. W. Mayer, "Low Temperature Migration of Silicon in Thin Layers of Gold and Platinum," Appl. Phys. Letters, 18, 178-181, March 1, 1971.

[3] J. Smit and H. P. J. Wijn, Ferrites, New York: J. Wiley and Sons, 1959, p. 229.

[4] H. P. Lemaire and W. J. Croft, "Ferrite Thin Films," J. Appl. Phys., 32, 46S-47S, March 1961.

[5] C. Kittel, Introduction to Solid State Physics, Third Edition, New York: J. Wiley and Sons, 1966, p. 461.

[6] E. Banks, N. H. Riederman, H. W. Schleuning, and L. M. Silber, "Preparation and Properties of Thin Ferrite Films," J. Appl. Phys., 32, 44S-45S, March 1961.

[7] L. R. Bickford, Jr., "Ferromagnetic Resonance Absorption in Magnetite Single Crystals," Physical Review, 78, 449-457, May 1950. 